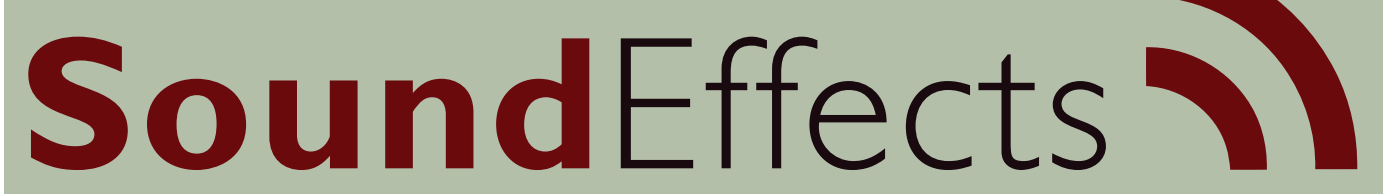

An Interdisciplinary Journal of Sound and Sound Experience

\title{
Christophe Magis
}

\section{'Do mess with Mister In-Between!'}

Musicological and socio-economic study of arrangement in advertising music covers

\section{Christophe Magis \\ Assistant Professor in Communication Studies \\ CEMTI - Université Paris 8, France \\ christophe.magis@gmail.com}




\begin{abstract}
Broadly speaking, analysis of television advertising music is usually focused on one or the other of two general types, original advertising music or pre-existing music. This reflects disciplinary dichotomies, where musicology and interpretative disciplines in general pursue textual analysis of original musical material while political economy analyses strategies towards copyright and licensing of existing music within the field of advertising and the cultural industries as a whole. This article tries to bridge this disciplinary gap by focusing on a hybrid category: advertising musical covers. Our aim is to demonstrate and discuss how communication and promotional strategies, economic lures and artistic wills all blend together in the musical arrangement of advertising covers. The focus on these 'in-betweens' affords an analysis of musical rationalization in advertising composition, which can be linked to socioeconomic strategies to be found within the field.
\end{abstract}

Most of the few analysts who have studied television advertising music have mainly focused on one or both of the two general types: original music composed to cover the needs of a special campaign, brand or product or pre-existing music mostly taken from the repertoires of recording companies (Julien, 1989; Huron, 1989; Scott, 1990; Graakjær, 2009a, 2009b; Bonde, 2009; Klein, 2009). ${ }^{1}$ Usually, the first type leads to musical typologies of semiotic functions which music can take on in connection with advertising; the second provides socio-economic analyses of the different strategies organised by actors such as creative workers in advertising, managers of recording companies, independent and integrated advertising music producers and artists in the advertising-musical field and, more broadly, in the wider field of the cultural industries.

The two general types of music in TV advertising are also the ones employed and promoted by the people who work within advertising music (Magis, 2013), and professionals and scholars appear to agree on the usage of these categories up to the point that no other category seems to reveal any kind of accuracy in a scientific analysis of advertising music. From our point of view these categories have indeed been useful for an analysis of such a corpus as long as they are considered as Weberian ideal-types; ${ }^{2}$ however, most advertising music does not fit either of these types perfectly and will, in effect, share some characteristics with both, possibly due to economic struggles between production actors or communicative needs. This is, at least, the result of our previous studies of French advertising music repertoires and advertising music production (cf. Magis, 2011, 2012). For various reasons, for instance, the mnemonic facilitation and cognitive appeal that pre-existing music offers comes with the matter of its expensiveness and, sometimes, its lack of interaction with the images or values of a brand, relations that any original music would take into account 
at the stage of composition, a lot of advertising music navigates between these two ideal-types. In fact, most advertising music represents a kind of 'in-between' situation in which all the different tensions between economic lures, social actor strategies, brand communication and audiovisual requirements tend to blend together in a special kind of musical work: the work of arrangement, which is handled mainly by composers who compose music for images (Adorno \& Eisler, 1951; Faulkner, 1983).

Thus, the purpose of this article is to present a special type of TV advertising music hybrid: covers, that is, advertising music created for a special purpose and which mostly consists of a new version of a pre-existing tune or melody (e.g. changed lyrics, instrumentation, singer, genre), and which can be analysed through the prism of the musical and economic role of the arrangement of advertising music. This analysis should then constitute a way to articulate two sets of problems which are rarely combined in the research field of cultural industries, - even though they are often presented as of primordial importance (cf. Hesmondhalgh, 2007, p. 40): the connection between economic lures or actors' socio-economic strategies and the reality of the produced texts. We will understand the advertising-musical text in the case of covers as the musical materialisation of the point where these strategies collide and show the different effects of the latter on the musical material.

To this end, this study is based both on an analysis of 38 interviews with composers, producers, creative workers and executives in advertising, sound designers and managers of recording companies located in the Parisian area and a musicological analysis of a corpus of 68 advertising spots from French television commercials from the previous decades. The three main pressures which are crystallised in the need for covers will be analysed independently. The first part will deal with the need for musical recognition in advertising creation; the second part will lead us towards the analysis of how different needs for appropriation and originality can commingle with this need for recognition; and the third part will explore the specific economic considerations behind these re-arrangements.

\section{Easy-to-remember and recognisable sound merchandise}

Cover music is, of course, not limited to advertising (cf. Plasketes, 2010). In the form of parody, adapting new lyrics to popular melodies is a very ancient practice in popular music (Dentith, 2000; Robine, 2004). In seventeenth-century Paris, song lyrics were published and sold on sheets with the mention 'Sur l'air de .... This canonical form of musical diffusion can even be traced back to early twentieth-century English popular classics. Broadsheets for popular songs were hawked until the 1920s and found regular consumers (Roberts, 1990). Covers also played an important role in the democratisation of records. The first popular music record producers used covers as a way of reducing the uncertainty of sales - typical of the nobody knows property that 
directs the economy of the cultural sector (Caves, 2000). They recorded the songs that used to be popular sheet music successes by various performers. Jazz music is also traditionally known for articulating a pool of standards and a myriad of different versions of each of these standards. Likewise, a lot of hits have become popular outside of their language-based borders, as bands recorded new versions in their own language. For instance, an international hit like the French song 'Comme d'habitude' has thus given birth to several versions in different languages by many different singers.

If the industrialisation of traditional music and popular music uses this technique often, it may to a large extent be due to its cognitive appeal, and advertising is probably the field where this appeal is most valued. Many researches have highlighted how important the question of remembrance is in the field of advertising (Mattelart, 1991; Fowles, 1996), and one of the major roles attributed to music in advertising is often linked to this question (cf. Graakjær \& Jantzen, 2009). This is also evident from the following interview extracts:

They [advertisers] always want the same 'trick' that links every TV spot and this 'trick' is memorisation. They want memorisation! It's a word that comes over and over all the time. We are constantly asked to do something that is easy to remember. (Independent advertising music producer, personal communication, 2011; translation by author)

Each time we have to create music for a spot, we will consistently be told, 'You have to do something that is easy to remember'. Or, 'You have to make a hit song like the hits we hear on the radio and that are easy to remember. It's your job ... We want people to sing our jingle like a hit song'. (Independent advertising music producer, personal communication, 2010; translation by author)

One of the greatest pressures exerted on creative workers and producers in connection with creation has to do with memorability. Then, from this perspective, being able to synchronise pre-existing music is a must, as the viewers will already be familiar with the music. The use of a known popular melody always seems to help, as all the informants told us:

Creating a jingle that draws on an already existing tune may provide some help; in fact, people already know it. You can change the lyrics, but people will already have a melodic frame to wedge into your new lyrics. (Advertising music producer for an advertising agency, personal communication, 2010; translation by author)

It is a popular trick in advertising music to reuse popular themes in order to play on affective memory (Julien, 1989, p. 246 sq.). In a 2007 issue of the advertising and media professional magazine Stratégies an editor showed much enthusiasm for the use of this technique in a TV commercial for Citroën (No. 1447, 8 March 2007, p. 34). Regardless of what Nicolai Graakjær points out about Danish advertising music in 
an analysis of the 'JYSK jingle' (Graakjær, 2009b), you often hear jingles adapted from famous existing tunes in the French advertising music repertoire. The technique is even popular to the point that it sometimes seems 'too easy' a trick according to some producers who have recently begun to defend advertisements of a high artistic quality - artistic quality is also sought in the use of music in advertisements (cf. Klein, 2009, p. 41 sq).

\section{A commercial like [X, using a musical cover], it's a very basic publicity technique! We all have to do that and it's not what we prefer. And so do I. We shouldn't forget that it is advertisement. They want to sell! And in order to advertise their product, sing their name in a tune that everybody knows is very effective! (Advertising music producer for an advertising agency, personal communication, 2010; translation by author)}

Aside from this 'trick', some musical rationalisation techniques are often used in the crafting of commercial covers, emphasising their recognisable quality. A very clear example of this from our corpus is the jingle that has been used in every commercial for the French mutual company MAAF since $2004 .^{3}$ In the spot the jingle comes on for five seconds after a sketch lasting twenty-five seconds, which has no background music and is sung on screen in a musical atmosphere.

This jingle is based on the chorus melody of 'C'est la ouate', a French hit from the 1980s sung by Catherine Loeb; ${ }^{4}$ it topped the charts from December 1986 to April 1987 and, thus, experienced wide media exposition. Its success has also been confirmed by different parodic adaptations made in the late 1980s and throughout the 1990s, which enhanced its earworm potential (Szendy, 2012) and, hence, justified its use as an easy-to-remember jingle. However, it is evident from the advertising adaptation that the memorability sought through musical rationalisation goes even further. Figures 1 and 2 offer a transcription of the original chorus and the advertising cover:
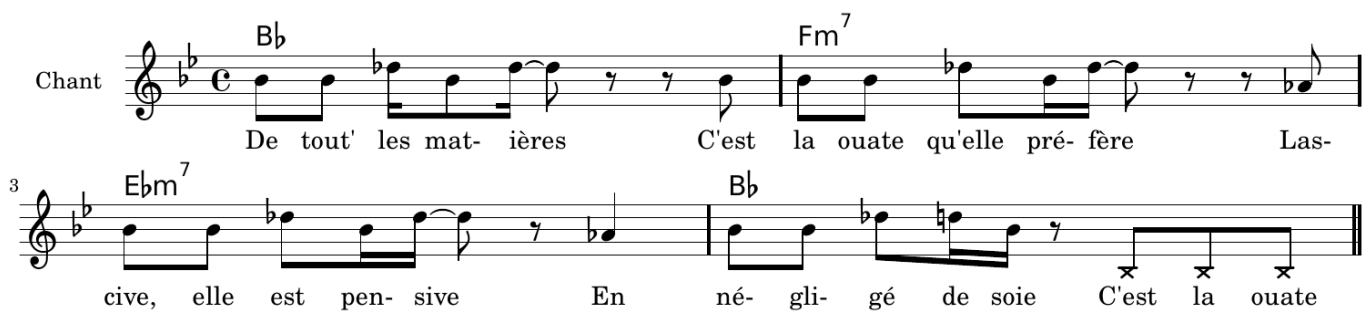

Fig. 1. 'C'est la ouate' - Chorus.

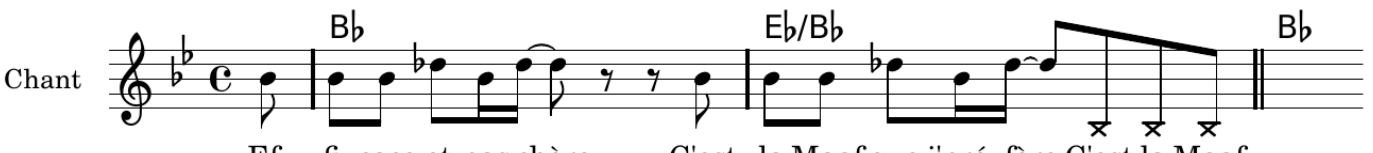

Ef- fi- cace et pas chère

C'est la Maaf que j'pré- fère C'est la Maaf

Fig. 2. Jingle MAAF. 
The jingle has been inserted into the two first sentences of the original chorus. We first see a modification at the level of the lyrics. The original lyrics and a translation are presented in Table 1.

Original chorus

Advertising cover
De toutes les matières C'est la ouate qu'elle préfère Lascive elle est pensive En négligé de soie ...C'est la ouate. Efficace et pas chère C'est la MAAF que j'préfère ...C'est la MAAF

\author{
Between every material \\ Her favourite is cotton wool \\ Lustful, she's thinking \\ In a silk negligée \\ ... It's cotton wool \\ Efficient and inexpensive \\ MAAF is my favourite \\ ... It's MAAF
}

Table 1. Lyrics, original and English translation.

In the second line the change is minimal; we find one of the economic principles of literary parody, whose simplest form is repetition (Genette, 1982). 'C'est la ouate qu'elle préfère' has become 'C'est la MAAF que j'préfère'; the assonance of the words 'ouate' and 'MAAF' is the same, making the substitution easier. The first line does not follow this rule. 'De toutes les matières' has become 'Efficace et pas cher'. The final rhyme remains the same, but in order to advertise the qualities of the mutual company another syllable has been added. And this change in the lyrics is not possible without a change of the musical phrase; in order to be able to say the entire new line, a pickup note has been added. Then the two phrases have the same number of notes, and the original effect of the beginning of the first phrase on the measure's first beat has been erased. Furthermore, whereas the rhythmic placement of the minor third (Db-Bb-Db) in the original chorus is not the same in the two sentences (although they are perhaps not as different as our transcription indicates); in the advertisement the melodic and rhythmic placements remain the same. Rendered identical, the advertising musical phrases have become a repetition of the same and the jingle then becomes even easier to remember. The repetition has been prepared in the melodic and rhythmic rationalisation of the cover. In the same vein, the harmonic simplification is even more flagrant. The original chorus was characterised by harmonic ambiguity between major and modal tones, while the advertising hammers the tonic $(\mathrm{Bb})$ at the bass throughout the jingle. Besides the fact that this note is the one on which the name of the company will be shouted at the end of the second measure, the harmonic effect is closed on a basic plagal cadence (I-IV-I). We see then how the pressure of memorability exerted on the production of advertising music tends to emphasise the easy-to-remember potential of a tune.

Drawing on Adorno's Marxian work on popular music, this 'easy-to-remember potential' is part of what we could call the 'commodity fetish character' of preexisting tunes. We will argue that most of what constitutes the power of these tunes 
is related to their exchange value; exchange-value is here manifest in their repetition. "Marx defines the fetish character of the commodity as the veneration of the thing made by oneself which, as exchange-value, simultaneously alienates itself from producer to consumer - "human beings". [...] This is the real secret of success' (Adorno, 1991, p. 38).

Alienation (or the 'secret of success') is here ensured by repetition that further provides advertising tunes with cognitive appeal. Relying on popular melodies that integrate their own diffusion needs with their compositional frame (i.e. what Adorno elsewhere calls 'standardization', cf. next section) and sing and show off their own fame and success (Szendy, 2012), covers are an adaptation of something which has already been tested and which can thus easily tolerate further rationalisation - notably following the memorability needs of advertising. This tolerated rationalisation can also appear at various stages.

\section{Originality of the known: arrangement as 'pseudo-individualisation'}

Even though memorisation is a very valuable and valued parameter in advertising and, therefore, in advertising music, another contradictory need seeks appropriation and originality. In his analysis of 'musical parodies' - his term for advertising covers - Jean-Rémy Julien (1989, p. 246 sq.) seems to overemphasise the musical influence of the first need to the detriment of the second, that is, what distinguishes a cover from its original. As an advertising music hybrid, covers are a way to capitalise on the affective appeal and cognitive power of hits while offering them new characteristics. As we just saw, these include especially commercial lyrics and enhanced melodic repetition. This first level of appropriation is not the most popular among creative workers in advertising and producers of advertising music. But there are more sophisticated levels.

Nevertheless, as will be (musically) highlighted in the next paragraphs, composers and producers are engaged to do a specific kind of work: arrangement. All the composers we interviewed insisted on the importance of arrangement in advertising music composition:

The guy that comes to advertising music thinking he's mainly going to compose very catchy choruses will quickly become disenchanted! Usually producers need us especially for rearrangement. And with the current trend towards pre-existing music synchronisation, it's even more the case. Mostly, they give you a tune and you have to do a string version or an acoustic version. (Advertising music composer, personal communication, 2011; translation by author)

For me it's the most interesting part of working with advertising music. Monday, you do an arrangement for this kind of ensemble, Tuesday it's in another genre, Wednes- 
day it's electric, Thursday it's acoustic and so forth ... And usually it's the same tune! You do your thing, send your tapes and the producer calls you back saying, 'It's great but a bit violent, will you soften it?' or, 'Can't you do the same thing in a rock version?' (Advertising music composer, personal communication, 2010; translation by author)

Advertising music is emblematic of this tendency highlighted by Adorno in film music as well as in popular music (Adorno, 1941, 1976, 1991): the divide between the two poles of music composition, theme writing and orchestration. Covers are the best acceptation of this divide; they presuppose a possibility of re-appropriation through arrangement. This then becomes a technique of what Adorno has called 'pseudo-individualization'. In Adorno's analysis, popular music conforms to standardisation; it is 'composed in such a way that the process of translation of the unique into the norm is already planned and, to a certain extent, achieved within the composition itself' (Adorno, 1971, p. 23). But as much as it conforms to standardisation, every popular music success needs to maintain a kind of autonomy that makes it different from other popular tunes. In this goal, popular music presents 'pseudoindividualized' characteristics - jazz improvisation being the extreme type - to 'camouflage the pre-digested' (cf. Adorno, 1976).

Music arrangement is where this 'pseudo-individualization' is prepared.

Because of popular music's ubiquitousness and vast scale of production it has been possible to establish in the collective mind a set of conventional musical 'colours' 'Spanish', 'pastoral', 'cow-boy', 'blue', 'hippie', 'punk', and so on - and arrangers and producers can simply lift the technical devices needed for these ready-made veneers off the shelf when needed. (Middleton, 1990, p. 50)

These 'conventional colours' are very useful in a field where distinction is also of great importance; memorability will not help if every commercial of a slot bears the same musical characteristics. Furthermore, advertising always seeks to give an 'effect of modernity' and an 'effect of novelty' (Mattelart, 1991). Then, in advertising music covers, pseudo-individualization is a good way to crystallise some 'added values' on new musical characteristics, as an informant put it in the following extract:

A cover offers a way of appropriation, of style definition. And here we think that brands are music producers. When one sees a spot, when one listens to a tune, one can appreciate the work of musical production. When it's done using an already known track, it's even more obvious.

Christophe Magis: Because people already know it?

Yes, so they can appreciate the difference. They already know it, so they have already 'internalised' the tune. We always already love a cover. A new tune, it takes 1, 2, 3 times. [...] A cover, we will like it right away and also appreciate the difference because we know the reference. So it would be, 'Ah! What a good idea to have changed 
the tempo'. [...] I'm convinced that it created a lot of added value for the brand! (Independent advertising music producer, personal communication, 2009; translation by author)

Also in popular music production, as analysed by Adorno, pseudo-individualization is then a way to increase the novelty appeal and, thus, the 'added value' of an already known popular tune for advertising purposes. The different musical materials can be 'adapted to current tastes', and the advertiser capitalises on these differences.

However, as Middleton shows in the above citation, most of these differences rely on conventional effects. One of the myths of pseudo-individualization is that even in producing originality it never gets far from the already known. The two generally organised rationalisation levels of pseudo-individualization that can be found in advertising covers are genres and stars, drawing on the pregnancy of those categories in the rationalisation of the rest of the music industry (Ryan, 1992; Hesmondhalgh, 2007).

\section{Rationalisation of 'pseudo-individualization': genres}

In the industrialisation of culture, genres represent a useful category, the terms of which 'operate as labels, not unlike brand names, that suggest to audiences the kind of pleasure they can attain by experiencing the product' (Hesmondhalgh, 2007, p. 23). In the way they spoke of advertising music rationalisation, all of our informants - music composers and producers as well as advertising executives - used terms related to genres to describe organised sets of sound characteristics connected to the identity of social groups or to the definition of typical values. For instance, jazz music was unrelentingly associated with 'classy' images and to 'upper-class' values:

\footnotetext{
There are some popular 'tricks' that easily make sense. For example, if we want to do something very classy, a very 'upper-class' atmosphere ... We can create a black and white visual ambiance with some jazz music. It sounds more 'nob' than a folk song. And when agencies send us black and white films for perfume or luxury products, we know that it is likely that they will ask for jazz music. (Advertising music producer for an advertising agency, personal communication, 2010; translation by author)
}

Popular music industrialisation has attached some sound sets to identity issues (Negus, 1999) to the extent that these reified links act as a form of common sense - or, put in a more Marxian way, a 'second nature'. In musical pseudo-individualization, then, advertising music relies on such musical common sense (Spalding, 1994). We can study rationalisation by looking at genre in our corpus. The most eloquent example is perhaps a spot created for the coffee brand Carte Noire. Like every French spot made for this brand since 1985, the music used in the $2004^{5}$ commercial is a cover of the very famous song 'Try to remember' of which many adaptations 
exist - this is true of many show tunes from the 1960s. We refer to the original version of the track.

In its form and instrumentation, the original title is typical of many of the Broadway ballads that draw on the formal and harmonic Tin Pan Alley style: an 'AABA' form where the 'A' parts follow the rhythm changes (I-VI-II-V). The instrumentation is limited to a piano and a double bass.

The cover only preserves the melody (here used as a jingle) and the first sentence 'Try to remember the kind of September' that is subject to variations. The time signature has been changed from three to four beats per measure, and the instrumentation has been modified; instead of the piano and double bass we are presented with a pedal distorted guitar playing palm mute, while an electric bass changes the harmonies. These have also been altered; for the rhythm changes typical of Broadway musical harmonies the cover substitutes a plagal movement (I-IV) and a perfect cadence ( $\mathrm{IV}-\mathrm{V}-\mathrm{I})$ more common in rock music changes.

The application of 'rock' genre characteristics is evident from different parts of the arrangement, but it does not liquidate the original melody that keeps its cognitive appeal when pseudo-individualization endows it with some kind of novelty.

\section{Rationalisation of 'pseudo-individualization': stars}

Another rationalisation category which is widely used in cultural industrialisation is the creation of stars, 'associating the name of star writers, performers and so on with texts' (Hesmondhalgh, 2007, p. 23). This category is also used a lot by our informants in advertising:

\section{Some tunes crystallise particular emotions so clearly that it's a gold mine for our work. Take Pink, for instance. Well, it's the archetype of the rebel and subversive girl. So, if we want to communicate these feelings, we just can use her music. (Advertising executive, personal communication, 2009; translation by author)}

In the music industry some musical values have come to be associated with certain performers. Sometimes those values can even be those attributed to more general genres, as the popular music semiotician Christian Lahusen puts it: 'Artists can become metonymies, synecdoches or prototypes of larger music styles ("living legends") if they are able to absorb, personify and, thus, exhaust, the musical type in their idiolect' (1996, p. 208). The interview extract above shows how the values supposedly attached to a star can rely mostly on the rock genre in which the performer is successful.

A commercial for the French bank Crédit Agricole released in $1995^{7}$ permits further analysis. The background music is based on ex-Beatle John Lennon's 'Imagine', though not in his version, but in a cover starring another legend in English-speaking music: Ray Charles. This change of performer comes with its own set of stylistic 
shifts. If Lennon's image is linked to the history of rock and pop which gives the original song a special instrumentation and a special vocal 'feeling', the cover by Charles transposes it to another genre, with other values, which attests to his legitimation as a performer. Where the original was known for its piano/voice and first verse with a sleek Alberti bass-like arrangement, the cover brings in new instruments - an electrical piano and bass and even a choir - in a typical instrumentation of soul records. The harmonies have also changed. The original uses mostly major triads and the rare seventh is slightly sketchy for melodic reasons, whereas the cover asserts the seventh, transforming major thirds to dominant seventh chords, which is normal in genres that descend from blues. In addition, a lot of rhythmic syncopations can be heard in the voice and the instruments; the original melody is not textually respected, but is used as a pretext for performers' and instruments' calls and answers - also typical of black-rooted music.

In fact, if the original song used many tokens typical of the pop ballad, a genre in which the original performer had reached legitimacy, the cover brings new values to the song by changing the performer and through different tokens that are known as parts of his idiolect. But the original tune is still there and recognisable, especially at the end of the commercial, the music of which is closer in resemblance to the original song bridge. The altered character is prominent at the beginning of the cover where the different 'feeling' represents a radical change, but under the effect of the power of the popular original tune everything seems finally sorted out for the chorus.

Hence, just as advertising covers capitalise on the cognitive appeal of a popular tune in order to meet memorability requirements, they also offer to meet originality expectations. But this originality still draws on conventional formulas. Like common popular music covers - from which they are issued - advertising covers are then characterised by techniques of pseudo-individualization that are to be sought in musical arrangements. And these shifts in arrangement also have economic repercussions.

\section{Political economy of 'pseudo-individualization' in advertising music covers}

In contemporary capitalism the popular, catchy tunes conform to a much organised economy. Advertising access to this pool of songs is subject to complex processes of negotiation with the music industry that made them popular. In a study of Popular music in advertising, Bethany Klein explains:

A synchronization license comprises two sets of rights: publishing and master use. Publishing rights refer to the written composition and come built-in to authorship of 
a song. [...] If a licensee wants to use the original version of a song in an ad [...] master use rights must also be secured. (2009, p. 25)

The first set of rights involves the writers, composers and editors of the original score; the second usually involves the producers of a specific recording. The prices for these licences are set at the end of the process of negotiation by the rights holders (usually the record company representatives) and the advertising executives. Negotiation can take many factors into account to determine the licencing price:

We have to understand what could be the right price for the tune, without selling it off and knowing that it could be interesting to promote our artists through advertising music exposition; or maybe it's a huge 'gold' and we can ask for a lot of money, especially if the advertiser is known for being 'big-headed'. Sometimes we can try gamble bets; we try to ask for more because it will be used worldwide, where we could objectively have accepted less; or we ask a little more precisely because the diffusion is narrow and we will get less exposure and fewer broadcasting rights - because after licencing rights we will also get the regular rights from the SACEM. (Synchronisation manager for a major recording company, 2011)

Then, if rearrangement in advertising music can be explained, as we have just seen, by various aspects like memorisation constraints and the need for fashionable sounds, it should not be forgotten that it also allows the use in advertising of popular tunes for half the price of the original song synchronisation licence. Because a cover comprises a re-recording of the tune, the original record is not used and, therefore, there is no need to pay master's rights (which usually represent half the price of a full synchronization licence):

There's an interest in taking a tune and record a new version. You then only pay the publishing rights and not the master's rights. [...] And re-recording is always much cheaper than paying the master's rights. Generally it's always fifty-fifty: there's a principle of 'less favoured mention'. So if the publishing rights are 50,000 euros, the master rights will be 50,000 euros [...]. On any popular standard, it's always cheaper to re-record. (Advertising music producer for an advertising agency, personal communication, 2009; translated by author)

Most of our informants explained the relative cost reduction that covers represent. The advantages of a cover are, then, the possibility of using an already popular tune with a more fashionable orchestration as well as the chance of paying only a part of the price of the original record. This economic characteristic of covers is combined with its other musical characteristics without being able to determine the salience of one or the other.

They never say, 'We don't want to have an old title, we want a very modern version of it', or, 'We just want to buy publishing rights and record a cheap version because we're lacking cash'. It's never said like this. It's always a bit of both. But we know it counts! 
(Synchronization manager for a major recording company, personal communication, 2010; translation by author)

Our informants seem to agree that a cover is a 'new' version - this is also important for legal reasons. This notion of 'individualising' or 'making new out of the old' is a major concern, legally speaking; it justifies paying only for publishing rights and it gives new arrangers and producers a kind of authorship. This side of pseudo-individualization which is absent in the original Adornian concept - this latter focusing mainly on the listener's affective response to type and variation, even though the main reasons for pseudo-individualization are economic (Adorno, 1941, 1976) appears to be central in a study of advertising music covers and, more generally, of advertising music, where authorship plays a major role (Klein, 2009, p. 23 sq.; Magis, 2013). When making a cover, the arranger, the advertising agency and often also the advertiser are co-producers of the new version, which grants them ownership of the new master's rights.

When we make a cover we are never editors of the tune, but we are producers [...]. So if they need the record for something else, to use it on a different thing, they have to ask my permission. Of course, in most contracts, they manage to turn it in a way so that we don't have anything to say; and more and more agencies and advertisers will ask for a co-production ownership to stay in control of it. [...] But if they release an album with my cover, I may make some money on it. (Independent advertising music producer, personal communication, 2010; translation by author)

In the presentation 'What is an Author?' Foucault explains how the 'author-function' has played and continues to play a major role in the control of the proliferation of meaning in modern societies' texts (Foucault, 1969). In our analysis the producing ownership of a cover's arranger and producer grants them control of the proliferation of the new meaning they put into a song, even though the song is not theirs in the first place; they are not the original authors of it. This producing ownership can be said to be included in this 'author-function', - which is not held by the actual author, but represents the group of actors who intervene in the construction of the author figure, whether it is recognised by the public or by authorship rights through which new actors are part of the economic co-ownership of a song.

Finally, some covers can limit 'pseudo-individualization' to its economic advantages. Though every informant insisted on the necessity of a real change in the re-recorded versions, actual advertising covers do not always respect this rule. Sometimes the expected result of a cover is to resemble the original. In our corpus a 2009 spot for Peugeot ${ }^{9}$ is a useful example. The background music is the famous tune 'Ac-cent-tchu-ate the Positive' written by Harold Arlin and Johnny Mercer and recorded by the latter in the 1940s. This song has also had a long career of adaptations and re-recordings; one of the most popular versions was recorded by 
Bing Crosby and The Andrews Sisters in $1944 .{ }^{10}$ This famous version is the reference of the advertising cover that performs the song in a musical style with a jazz 'big band' orchestration. This musical theme is followed by the advertising images of old-fashioned American cars from the 1950s and 1960s. The advertising cover also simulates the characteristic instrumentation, but it does not only imitate the instrumentation. If we pay attention to the voice, we realise that the cover seems to imitate Crosby's particular tone of voice, especially in the first sentences ('You gotta accentuate the positive/Eliminate the negative/Latch on to the affirmative'). The cover, which seeks to resemble the original, is justified though by the different kinds of voice imitations: many specific crooner voices are imitated (e.g. the characteristic growl of Armstrong's voice), and eventually the entire musical crooner hall of fame is assembled. Then, differing from the original record (probably for economic reasons) to accentuate its general musical genre characteristics, the cover in fact comes as close as possible to its original reference.

\section{Conclusion}

'Don't mess with Mister In-Between!' is the advice of the last song analysed here. In the common style of many Broadway musical songs, the lyrics of this tune, which invites the listener to affirm an uncompromisingly positive spirit without 'inbetweens', is not a good example of what constitutes advertising covers. Covers represent a perpetual 'in-between': an intermediary state between the two ideal-types in advertising, namely original music composition and pre-existing music synchronisation. This intermediary state is to a great extent determined by the struggling different strategies of the different actors within the advertising music field (cf. Magis, 2013). These different strategies centre on several constraints - either cultural, economic or in terms of communication - that ultimately rest on music itself. Advertising music covers then appear in the particular cases - which are not that rare, according to the informants - described here by a music producer for an advertising agency:

There are tunes that we like because they are 'catchy', but they have two major flaws: 1) They aren't 'in', and 2) we don't have enough money to buy their licencing rights. Under these conditions, we can make a cover; we keep the music, but change the style and we re-record. (Personal communication, 2010; translation by author)

It should now be clear that the possibility of using covers in advertising is furthered both by the fact that arrangement has been separated from composition as a result of popular music industrialisation and also by the particular situation concerning modern music authorship that considers the re-arrangement of songs an individualising practice. As in all popular music, arrangements consist here of a 'colouring 
in' that may draw on conventional popular music business categories to highlight different versions of the same music, which has a particular appeal in itself: its commodity characteristic.

It is in these 'in-betweens' that the struggles and transversal problems of music creation, communicative needs and economic lures in the advertising music field become visible. This article has only outlined a few ways to consider them, but it seems that these 'in-betweens' should be subjected to further research as they offer, for this repertoire, a way to analyse the socio-economic determinations of musical texts as well as the compositional responses to communicative needs.

\section{References}

Adorno, T.W. (1941). On popular music. In: Studies in Philosophy and Social Sciences (pp. 17-48), 9. New York, NY: Institute of social research.

Adorno, T.W. (1976). Introduction to the Sociology of Music. New York, NY: Continuum.

Adorno, T.W. (1991). The Culture Industry: Selected Essays on Mass Culture. London: Routledge.

Adorno, T.W., \& Eisler, H. (1951). Composing for the Films. New York, NY: Continuum.

Bonde, A. (2009). On the Commercialization of Shostakovitch's 'Waltz No. 2'. In: Graakjær, N., \& Jantzen, C. (Eds.), Music in advertising: Commercial Sounds in Media Communications and Other Settings. Aalborg: Aalborg University Press.

Dentith, S. (2000). Parody. London: Routledge.

Faulkner, R. (1983). Music on Demand: Composers and Careers in the Hollywood Film Industry. New Brunswick, NJ: Transaction Publishers.

Fowles, J. (1996). Advertising and Popular Culture. Thousand Oaks, CA: Sage.

Genette, G. (1982). Palimpsestes: La littérature au second degré. Paris: Seuil.

Graakjær, N., \& Jantzen, C. (Eds.) (2009). Music in advertising: Commercial Sounds in Media Communications and Other Settings. Aalborg: Aalborg University Press.

Graakjær, N., \& Jantzen, C. (2009). Mapping Research on Music in TV Commercials. In: Graakjær, N., \& Jantzen, C. (Eds.), Music in advertising: Commercial Sounds in Media Communications and Other Settings. Aalborg: Aalborg University Press.

Graakjær, N. (2009a). Music in TV Commercials: Formats, Frequencies and Tendencies. In: Graakjær, N., \& Jantzen, C. (Eds.), Music in advertising: Commercial Sounds in Media Communications and Other Settings. Aalborg: Aalborg University Press.

Graakjær, N. (2009b). The JYSK Jingle: On the Use of Pre-Existing Music as a Musical Brand. In: Graakjær, N., \& Jantzen, C. (Eds.), Music in advertising: Commercial Sounds in Media Communications and Other Settings. Aalborg: Aalborg University Press.

Hesmondhalgh, D. (2007). The Cultural Industries, Thousand Oaks, CA: Sage.

Huron, D. (1989). Music in Advertising: An Analytic Paradigm. The Musical Quarterly, 73: 557-574.

Julien, J.-R. (1989). Musique et publicité: Du cri de Paris... aux messages publicitaires radiophoniques et télévisés. Paris: Flammarion.

Klein, B. (2009). As Heard on TV: Popular Music in Advertising. Farnham: Ashgate.

Lahusen, C. (1996). The Rhetoric of Moral Protest: Public Campaigns, Celebrity Endorsement, and Political Mobilization. New York, NY: De Gruyter.

Magis, C. (2011). Intertextualités à l'œuvre dans la chanson publicitaire: le cas de la parodie. Eidôlon, 94, 161-172. 
Magis, C. (2012). Lanalyse esthétique des 'contenus' des industries culturelles, une perspective critique?: Propositions d'analyse socio-économique et musicologique de la musique de publicité. In: Actes du colloque "Où en est la critique en communication". Montréal.

Magis, C. (2013). Entre droit d'auteur et conseil en communication: analyse socio-économique des mutations conjointes de l'industrie musicale et de l'industrie de la publicité. In: Ballarini, L., \& Delavaud, G. (Eds.), Nouveaux territoires médiatiques. Rennes: Apogée.

Mattelart, A. (1991). Advertising International: The Privatisation of the Public Sphere. London: Routledge. Middleton, R. (1990). Studying Popular Music. Philadelphia, PA: Open University Press.

Negus, K. (1999). Music Genres and Corporate Culture. London: Routledge.

Plasketes, G. (ed.) (2010). Play it Again: Cover Songs in Popular Music. Farnham: Ashgate.

Roberts, R. (1990). The Classic Slum: Salford Life in the First Quarter of the Century. New York, NY: Penguin Books.

Robine, M. (2004). Il était une fois la chanson française. Paris: Fayard.

Ryan, B. (1992). Making Capital from Culture. New York, NY: De Gruyter.

Scott, L. (1990). Understanding Jingles and Needledrops: A Rhetorical Approach. Journal of Consumer Research, 17(2): 223-236.

Spalding, E. (1994). Intertextuality in Advertising Music on the Radio: The Case of CFOX-FM. Canadian Journal of Communication, 19(2).

Szendy, P. (2012). Hits: Philosophy in the Juke-Box. Bronx, NY: Fordham University Press.

Weber, M. (1997). The Methodology of the Social Sciences. New York, NY: Free Press.

\section{Notes}

1 A precise review of 40 years of international research on the theme can be found in Graakjær \& Jantzen, 2009.

2 'An ideal-type is formed by the one-sided accentuation of one or more points of view by the synthesis of a great many diffuse, discrete, more or less present and occasionally absent concrete individual phenomena, which are arranged according to those one-sidedly emphasized viewpoints into a unified analytical construct' (Weber, 1997, p. 90).

3 The spot on which our analysis is based can be found at: http://www.ina.fr/pub/finances-et-assurances/video/PUB2632197175/maaf-assurances-mrh-version-36-secondes.fr.html (Accessed on 3 February 2013). It is one of the first spots in the series, but they all share the same structure.

4 Caroline Loeb, 'C'est la ouate' (3’48"), EP: C'EST LA OUATE, Barclay, 885 341-7, 1986.

5 http://www.ina.fr/pub/alimentation-boisson/video/PUB2689121072/carte-noire-vol-doiseau.fr.html (Accessed on 4 February 2013).

6 From the musical The Fantasticks. MGM Records E3872 OC, 1963.

7 http://www.ina.fr/economie-et-societe/vie-economique/video/PUB487253133/credit-agricole-imagine-98.fr.html (Accessed on 4 February 2013).

8 The SACEM is the French professional society that collects payment of music rights (exposition and reproduction) and distribute them to the authors, composers and music publishers.

9 http://www.youtube.com/watch?feature=player_embedded\&v=sjgysdSHhzU (Accessed on 4 February 2013).

10 Cf. Bing Crosby: Academy Award Winner and Nominees, MCA/Decca 088 112274-2, 2000. 